\title{
Metabolic syndrome remission after Roux-en-Y gastric bypass or sleeve gastrectomy
}

This article was published in the following Dove Press journal: Diabetes, Metabolic Syndrome and Obesity:Targets and Therapy 20 September 2017

Number of times this article has been viewed

\author{
Ibrahim Nassour' \\ Jaime P Almandoz ${ }^{2}$ \\ Beverley Adams-Huet ${ }^{3,4}$ \\ Sachin Kukreja ${ }^{5}$ \\ Nancy Puzziferri ${ }^{1,5}$ \\ 'Department of Surgery, ${ }^{2}$ Department \\ of Internal Medicine, Division of \\ Endocrinology, ${ }^{3}$ Department of \\ Clinical Sciences, ${ }^{4}$ Department of \\ Internal Medicine, University of \\ Texas Southwestern Medical Center, \\ ${ }^{5}$ Department of Surgery, Veterans \\ Affairs North Texas Health Care \\ System, Dallas, TX, USA
}

Background: Bariatric surgery is known to decrease weight and the prevalence of comorbidities, but there is little evidence on the differential effect of Roux-en-Y gastric bypass (RYGB) and sleeve gastrectomy (SG) on the remission of the aggregate outcome, metabolic syndrome, 4 years after surgery. The purpose of this study was to determine the effectiveness of RYGB and SG on metabolic syndrome in veterans.

Methods: We retrospectively reviewed consecutive patients who underwent SG and RYGB at the Dallas Veterans Affairs Medical Center from 2003 to 2012. We determined the effect of both the operations on the remission of metabolic syndrome, its individual components, and mediumterm morbidity and mortality. A sensitivity analysis was performed using propensity matching. Results: A total of 266 patients were identified (159 RYGB and 107 SG) with $96 \%$ follow-up after 4 years. The mean age of the cohort was 51.4 years; the majority of patients were male $(59 \%)$ and Caucasian (69\%). RYGB patients had a greater mean body mass index and were more likely to have hypertension or hypertriglyceridemia. RYGB was associated with a similar metabolic syndrome remission to SG $(37.6 \%$ vs $26.8 \% ; P=0.09)$. The percentage of weight loss was $26.5 \%$ after RYGB and $10.8 \%$ after SG at 4 years post operation $(P<0.01)$. Predictors of metabolic syndrome persistence were male gender, type 2 diabetes, and low high-density lipoprotein. While both the operations were associated with similar mortality (RYGB 4.4\%, SG $2.8 \% ; P=0.74)$, RYGB was associated with a greater rate of morbidity.

Conclusion: RYGB and SG seem to be associated with similar remission rates of metabolic syndrome at 4 years. RYGB yields greater weight loss with greater medium-term complications. Keywords: bariatric surgery, weight loss, diabetes, hypertension, hyperlipidemia

\section{Introduction}

Metabolic syndrome is a conglomeration of interrelated risk factors that are associated with obesity and the development of atherosclerotic cardiovascular disease. ${ }^{1}$ International consortiums dedicated to cardiovascular and metabolic health recognize metabolic syndrome as a chronic disease that causes significant loss of productivity, excess mortality, and a significant expenditure of healthcare dollars. ${ }^{2}$

Bariatric surgery, an effective treatment for obesity ${ }^{3,4}$ and type 2 diabetes mellitus (T2DM), ${ }^{5,6}$ also improves metabolic syndrome and reduces cardiovascular mortality in cohorts followed up for 5-18 years after surgery. ${ }^{7-10}$ We assume, but do not have supporting evidence for, similar improvements in metabolic syndrome after sleeve gastrectomy (SG), which has surpassed Roux-en-Y gastric bypass (RYGB) as the most commonly performed bariatric operation in the USA ( $52 \%$ vs $27 \%$ in 2014$).{ }^{11}$
Correspondence: Nancy Puzziferri Department of Surgery, University of TX 75390-8548, USA

$\mathrm{Tel}+\mathrm{I} 2146489685$

Fax + I 2146486700

Email Nancy.puzziferri@

UTSouthwestern.edu 
RYGB may yield greater weight loss than SG, but differences in the remission of comorbidities and complication rates are less well-studied. Most SG studies have limited follow-up and are unable to report on the durability of weight loss or improvements in metabolic syndrome. ${ }^{12-15}$ Moreover, most bariatric studies predominantly enroll female subjects, and although weight loss results may be similar between sexes, metabolic improvements or complication rates may not be generalizable to men. ${ }^{16,17}$

In this study, we retrospectively evaluated the remission of metabolic syndrome and its individual components 4 years after RYGB or SG in a US veteran population. In addition, we examined the complication rates of both the operations.

\section{Methods}

\section{Study design and patients}

This was a retrospective review of the electronic medical records of all consecutive patients who underwent either RYGB or SG at the Dallas Veterans Affairs Medical Center in Dallas, TX, USA from 2003 to 2012. The center's institutional review board approved the study. Obtaining patient consents was waived as this was a retrospective study with minimal risks. All patients met the criteria for bariatric surgery set by the National Institutes of Health consensus conference. ${ }^{3}$ Patients with a body mass index (BMI) of $>40 \mathrm{~kg} / \mathrm{m}^{2}$ or with a BMI of $>35 \mathrm{~kg} / \mathrm{m}^{2}$ and one or more significant comorbid conditions, including T2DM, hyperlipidemia, and hypertension, were offered bariatric surgery. The choice of bariatric procedure was based on patient preference, perioperative risk assessment by the bariatric team, instrument availability, and the adoption of new operations (no SGs were performed prior to 2007). Patients were allowed to choose either operation if they did not have cirrhosis, end-stage renal disease, or cardiac dysfunction that limited activities of daily living. Otherwise SG was offered. The preoperative risk assessment was conducted by the bariatric team, which included surgeons, hepatologists, nephrologists, and cardiologists. Instrument availability refers to a 6-month period when RYGB instruments were not available and the patients could either undergo an SG or postpone their operation until all instruments were again available.

\section{Operative procedures RYGB}

Roux limbs of $\sim 110 \mathrm{~cm}$, gastric pouches of $20-30 \mathrm{~mL}$, and jejunojejunostomies $40-45 \mathrm{~cm}$ distal to the ligament of Treitz were created. The open RYGBs (88\%) had hand-sewn gastrojejunostomies and jejunojejunostomies; the gastric pouches were created with a TA 60 stapler (Medtronic,
Minneapolis, MN, USA). Open gastrojejunostomies were anti-gastric with retrocolic Roux limbs. Leak tests were not performed. The laparoscopic RYGBs (12\%) had $25 \mathrm{~mm}$ circular endostapled gastrojejunostomies and $60 \mathrm{~mm}$ endostapled jejunojejunostomies. Leak tests were performed with an esophagoduodenoscopy insufflation, distal occlusion, and submersion in sterile saline.

\section{SG}

The gastrosplenic omentum was dissected from $8 \mathrm{~cm}$ proximal to the pylorus to the level of the left crus of the diaphragm. The angle of His was completely mobilized. A 32-French calibration bougie was advanced into the stomach and a longitudinal restrictive gastrectomy was performed using buttressed endostaplers. Care was taken to reduce the posterior fundus throughout the dissection. A leak test was performed with an esophagoduodenoscopy insufflation, distal occlusion, and submersion in sterile saline. All sleeve gastrectomies were performed laparoscopically.

\section{Data collection}

Study coordinators and surgical residents were trained to collect the following patient information from the electronic medical record: demographics, weight, height, hemoglobin A1c (HbA1c), fasting blood glucose levels, blood pressures, lipid panels, medication usage for T2DM, hypertension and hyperlipidemia, and late surgical complications ( $>30$ days postsurgery). Measurement time points were at baseline (preoperation) and a minimum of 4 years postoperation. Weight was extracted annually for up to 4 years.

\section{Outcome variables}

Weight loss outcomes were reported as the change in weight, BMI, percent of total weight loss, and excess weight loss (EWL). T2DM was defined as HbA1c of $\geq 6.5 \%$ or the use of diabetes medications. Metabolic syndrome was defined as having three or more of the following criteria: ${ }^{18}$

1. Fasting blood glucose of $\geq 100 \mathrm{mg} / \mathrm{dL}$ ( $\geq 5.6 \mathrm{mmol} / \mathrm{L})$, $\mathrm{HbA} 1 \mathrm{c}$ of $\geq 5.7 \%$, a diagnosis of $2 \mathrm{DM}$, or a prescription for diabetes medication. ${ }^{19}$

2. BMI of $\geq 30 \mathrm{~kg} / \mathrm{m}^{2}$ as a surrogate for waist circumference of $\geq 102 \mathrm{~cm}$ (male) and $\geq 89 \mathrm{~cm}$ (female).

3. Triglycerides (TGs) of $\geq 150 \mathrm{mg} / \mathrm{dl}$, or a prescription for hypertriglyceridemia medication.

4. High-density lipoprotein cholesterol (HDL-C) of $<40 \mathrm{mg} /$ $\mathrm{dL}$ for males $(<2.2 \mathrm{mmol} / \mathrm{L})$ or $<50 \mathrm{mg} / \mathrm{dL}$ for females $(<2.8 \mathrm{mmol} / \mathrm{L})$. 
5. Hypertension defined as blood pressure of $\geq 130 / 85 \mathrm{~mm}$ $\mathrm{Hg}$ or a prescription for antihypertensive medication.

\section{Statistical analyses}

Results are expressed as means with standard deviations and count frequencies with percentages unless otherwise specified. Categorical outcomes were compared between the two groups with Fisher's exact test, and continuous variables were compared with a two-sample $t$ test or Wilcoxon rank sum test. Changes in weight through 4 years of follow-up were compared between the SG and RYGB groups with mixed effects repeated measures linear models. In patients with established metabolic syndrome prior to surgery, logistic regression was used to assess presurgery predictors of metabolic syndrome persistence. Independent variables included in the logistic models were gender, age, and BMI; metabolic variables were included where $P<0.20$.

Due to baseline imbalances of weight and metabolic characteristics between the SG and RYGB groups, a sensitivity analysis was performed using propensity score matching. Multiple logistic regression was implemented to generate a propensity score for all patients according to the type of operation (RYGB vs SG), with the following covariates: age, gender, race/ethnicity (African American, non-Hispanic white, others), presurgery weight, BMI, the presence of diabetes and dyslipidemia, and metabolic syndrome features of elevated glucose, blood pressure, TGs, and low HDL cholesterol. Patients in the two groups were then matched through a greedy 8-1 digit-matching algorithm resulting in 65 RYGB and 65 SG patients. Standardized differences between groups were assessed to establish whether adequate balance was achieved. Analyses were then performed on the two matched groups.

Unless otherwise noted, two-sided $P$ values of $\leq 0.05$ were considered statistically significant. Analyses were conducted using SAS software, version 9.4 (SAS Institute, Cary, NC, USA).

\section{Results}

\section{Baseline characteristics}

The cohort consisted of all 266 consecutive patients who underwent bariatric surgery during the study period. Data were available for 254 patients $(96 \%$ of the total cohort; 10 deceased, 244 alive, 12 lost to follow-up) at 4 years (Figure S1). While all patients had annual weight and complications data, 6 patients were missing complete data on metabolic syndrome criteria, yielding 238 patients available for the assessment of metabolic syndrome. Patients underwent RYGB $(n=141 ; 59 \%)$ or SG $(n=97 ; 41 \%)$. The mean age of the cohort was 51.4 years with a male (59\%) and Caucasian $(69 \%)$ predominance. The baseline characteristics by group according to operation are summarized in Table 1. The groups had similar mean ages and gender/race frequencies. The RYGB group weighed significantly more than the SG group, with a mean preoperative weight of $137 \mathrm{~kg}$ compared to $124 \mathrm{~kg}(P<0.01)$, and a mean preoperative BMI of $45.5 \mathrm{~kg} /$ $\mathrm{m}^{2}$ compared to $40.7 \mathrm{~kg} / \mathrm{m}^{2}(P<0.01)$, respectively.

RYGB patients were more likely to have hypertension (RYGB $96.5 \%$ vs SG $87.6 \% ; P=0.02$ ) and hypertriglyceridemia (RYGB $59.7 \%$ vs SG $37.9 \% ; P<0.01$ ). The prevalence of hyperglycemia and low HDL was similar between groups.

\section{Metabolic syndrome remission}

RYGB significantly reduced all metabolic syndrome components, while SG significantly reduced all metabolic syndrome components except hypertriglyceridemia and hyperglycemia (Table 2). More patients who underwent RYGB achieved a BMI of $<30 \mathrm{~kg} / \mathrm{m}^{2}$ compared to $\mathrm{SG}(31.9 \%$ vs $17.5 \% ; P=0.02$ ). In addition, RYGB was associated with a greater decrease in the prevalence of hypertriglyceridemia (from $60.1 \%$ to $21.7 \%$ ) compared to $\mathrm{SG}$ (from $37.2 \%$ to $29.8 \% ; P<0.01)$. There was no significant difference between operations in improving hyperglycemia, low HDL, or hypertension.

Metabolic syndrome remission occurred in both the surgical groups, but there was no significant difference of remission rates between the RYGB (37.6\%) and the SG group $(26.8 \% ; P=0.09)$. With propensity matching, similar metabolic syndrome remission was again found after both operations (RYGB 40.0\%, SG 27.7\%; $P=0.34$; Table S1).

The effect of surgery on metabolic syndrome was determined for the whole cohort after adjusting for clinically and statistically significant factors affecting the outcomes (Table 3). We found that SG patients had a 1.89 odds ratio (OR) (95\% CI, 0.91-3.91) of having persistent metabolic syndrome at 4 years compared to RYGB patients, which supports our analysis in the matched and unmatched cohort that there may be no significant difference between both operations on metabolic syndrome remission at 4 years.

Predictors of metabolic syndrome persistence 4 years post operation were male gender (OR, 2.28; 95\% CI, 1.14-4.56), a preoperative diagnosis of T2DM (OR, 3.33; 95\% CI, 1.71-6.50), and preoperative low HDL (OR, 2.28; 95\% CI, $1.17-4.48)$. 
Table I Patients' demographics and baseline comorbidities

\begin{tabular}{|c|c|c|c|c|c|c|c|}
\hline \multirow[t]{2}{*}{ Characteristics } & \multicolumn{3}{|c|}{ Overall cohort } & \multicolumn{4}{|c|}{ Matched cohort } \\
\hline & $\begin{array}{l}\text { RYGB } \\
(n=\mid 4 I)\end{array}$ & $\begin{array}{l}\text { SG } \\
(n=97)\end{array}$ & $P$-value & $\begin{array}{l}\text { RYGB } \\
(n=65)\end{array}$ & $\begin{array}{l}\text { SG } \\
(n=65)\end{array}$ & $\begin{array}{l}\text { Standardized } \\
\text { difference }\end{array}$ & $\overline{P \text {-value }}$ \\
\hline Age, years & $5 I . I(8.1)$ & $51.9(10.4)$ & 0.53 & $50.9(9.1)$ & $51.5(10.1)$ & 0.06 & 0.72 \\
\hline Males, n (\%) & $80(56.7)$ & $61(62.9)$ & 0.35 & $37(56.9)$ & $29(60.0)$ & 0.06 & 0.86 \\
\hline Race, n (\%) & & & 0.11 & & & & 0.78 \\
\hline Caucasian & $104(73.8)$ & $60(61.9)$ & & $40(61.5)$ & $44(67.7)$ & 0.13 & \\
\hline African American & $24(17.0)$ & $21(21.7)$ & & $16(24.6)$ & $14(21.5)$ & 0.07 & \\
\hline Other & $13(9.2)$ & $16(16.5)$ & & $9(13.9)$ & $7(10.8)$ & 0.09 & \\
\hline Weight, kg & $137(26)$ & $124(23)$ & $<0.01$ & $126(20)$ & $126(22)$ & 0.01 & 0.95 \\
\hline $\mathrm{BMI}, \mathrm{kg} / \mathrm{m}^{2}$ & $45.5(6.4)$ & $40.7(4.8)$ & $<0.01$ & $42.0(4.8)$ & $42.1(4.6)$ & 0.01 & 0.95 \\
\hline Hyperglycemia, n (\%) & $103(73.1)$ & $77(79.4)$ & 0.29 & $50(76.9)$ & $49(75.4)$ & 0.04 & 1.0 \\
\hline Type 2 diabetes, $\mathrm{n}(\%)$ & $78(55.3)$ & $47(48.5)$ & 0.36 & $33(50.8)$ & $30(46.2)$ & 0.09 & 0.73 \\
\hline $\mathrm{HbAlc}, \%$ & $6.6(1.2)$ & $6.7(1.2)$ & 0.73 & $6.7(1.3)$ & $6.6(1.2)$ & 0.15 & 0.50 \\
\hline Fasting plasma glucose, $\mathrm{mg} / \mathrm{dL}$ & $125(48)$ & $|2|(43)$ & 0.57 & $120(38)$ & $120(37)$ & 0.004 & 0.98 \\
\hline Oral diabetes medication, $\mathrm{n}(\%)$ & $63(44.7)$ & $37(38.1)$ & 0.35 & $26(40.0)$ & $24(36.9)$ & 0.06 & 0.86 \\
\hline Insulin treatment, n (\%) & $26(18.4)$ & $22(22.7)$ & 0.51 & $12(18.5)$ & $14(21.5)$ & 0.08 & 0.83 \\
\hline \multirow[t]{2}{*}{ Insulin total daily dose, $U$} & $139[80--169]$ & 90 [60-155] & 0.54 & $140[80-190]$ & $110[65-190]$ & 0.16 & 0.74 \\
\hline & $\mathrm{n}=24$ & $\mathrm{n}=18$ & & $\mathrm{n}=\mathrm{i}$ & $\mathrm{n}=12$ & & \\
\hline Hypertension, n (\%) & $136(96.5)$ & $85(87.6)$ & 0.02 & $61(93.9)$ & $62(95.4)$ & 0.07 & 1.0 \\
\hline Systolic blood pressure, $\mathrm{mm} \mathrm{Hg}$ & $132(16)$ & $|3|(\mid 4)$ & 0.52 & $133(18)$ & $130(13)$ & 0.19 & 0.30 \\
\hline Diastolic blood pressure, $\mathrm{mm} \mathrm{Hg}$ & $73(11)$ & $75(10)$ & 0.15 & $75(\mathrm{II})$ & $75(\mathrm{II})$ & 0.05 & 0.76 \\
\hline Hypertension medication, $n(\%)$ & $116(82.3)$ & $70(72.2)$ & 0.08 & $50(76.9)$ & $51(78.5)$ & 0.04 & 1.0 \\
\hline Hypertriglyceridemia, n (\%) & $83(59.7)$ & $36(37.9)$ & $<0.01$ & $32(50.0)$ & $31(49.2)$ & 0.02 & 1.0 \\
\hline Triglycerides, mg/dL & 174 [108-229] & 122 [89-200] & 0.01 & 162 [92-239] & $153[102-216]$ & 0.04 & 0.82 \\
\hline Low high-density lipoprotein, n (\%) & $70(50.4)$ & $46(48.4)$ & 0.79 & $33(51.6)$ & $31(49.2)$ & 0.05 & 0.86 \\
\hline $\mathrm{HDL}, \mathrm{mg} / \mathrm{dL}$ & $44(12)$ & $43(13)$ & 0.6 & $42(\mathrm{II})$ & $44(12)$ & 0.10 & 0.58 \\
\hline Lipid-lowering medication, $n \%$ & $82(58.2)$ & $59(60.8)$ & 0.69 & $38(58.5)$ & $40(61.5)$ & 0.06 & 0.86 \\
\hline
\end{tabular}

Notes: Continuous variables are summarized as mean (standard deviation) or median [25th-75th percentile]. For skewed variables, the parametric and nonparametric comparisons are very similar (nonparametric reported for insulin dose and triglycerides).

Abbreviations: BMI, body mass index; HDL, high-density lipoprotein; RYGB, Roux-en-Y gastric bypass; SG, sleeve gastrectomy.

Table 2 Prevalence of metabolic syndrome and its components before ("pre") and 4 years following ("post") RYGB and SG for the entire cohort

\begin{tabular}{|c|c|c|c|c|c|c|c|}
\hline & \multicolumn{2}{|c|}{ RYGB (n = |4I) } & \multirow{2}{*}{$\begin{array}{l}\text { Paired test } \\
\text { P-value } \\
\text { (McNemar) }\end{array}$} & \multicolumn{2}{|c|}{ SG $(n=92)$} & \multirow{2}{*}{$\begin{array}{l}\text { Paired test } \\
P \text { (McNemar) }\end{array}$} & \multirow{2}{*}{$\begin{array}{l}\text { Interaction } \\
P \text {-value }\end{array}$} \\
\hline & Pre, n (\%) & Post, n (\%) & & Pre, n (\%) & Post, n (\%) & & \\
\hline Obesity & $|4|(100)$ & $96(68.1)$ & $<0.01$ & $97(100)$ & $80(82.5)$ & $<0.01$ & 0.02 \\
\hline Hyperglycemia & $106(75.2)$ & $89(63.1)$ & $<0.01$ & $74(81.3)$ & $67(73.6)$ & 0.09 & 0.53 \\
\hline Hypertriglyceridemia & $83(60.1)$ & $30(2 \mid .7)$ & $<0.01$ & $35(37.2)$ & $28(29.8)$ & 0.18 & $<0.01$ \\
\hline Low HDL-C & $69(50)$ & $31(22.5)$ & $<0.01$ & $45(48.4)$ & $15(16.1)$ & $<0.01$ & 0.38 \\
\hline Hypertension & $136(96.5)$ & I I 8 (83.7) & $<0.01$ & $85(87.6)$ & $65(67.0)$ & $<0.01$ & 0.45 \\
\hline Metabolic syndrome & $125(88.7)$ & $72(5 \mathrm{I} .1)$ & $<0.01$ & $82(84.5)$ & $56(57.7)$ & $<0.01$ & 0.09 \\
\hline
\end{tabular}

Abbreviations: HDL-C, high-density lipoprotein cholesterol; RYGB, Roux-en-Y gastric bypass; SG, sleeve gastrectomy.

\section{Weight change}

RYGB patients lost more weight than SG patients at 4 years post operation (Figure 1). The mean weight loss after RYGB was $36.3 \mathrm{~kg}(P<0.01)$ and $13.4 \mathrm{~kg}$ after SG $(P<0.01)$. The percentage weight loss was $26.5 \%$ at 4 years after RYGB and $10.8 \%$ after SG $(P<0.01$, each pre- vs postoperation). The greatest percent weight change for both the operations occurred at 1 year (RYGB 28.7\%, SG 16.8\%). The decrease in BMI and weight were more pronounced in RYGB. After propensity matching, a similar weight loss trend and magnitude were found (Figure 2).

\section{Complications}

From 1 to 4 years after surgery, 7 patients (4.4\%) died after RYGB, and 3 (2.8\%) died after SG. RYGB was associated with a greater rate of morbidity compared to SG (Table 4). RYGB had significantly greater rates of reoperation, cholecystectomy, ulcer, and vitamin $\mathrm{B}_{12}$ deficiency. These 
Table 3 Predictors of metabolic syndrome presence at 4-year follow-up using the entire cohort

\begin{tabular}{lll}
\hline MetS at 4-year follow-up & Odds ratio & $\mathbf{9 5 \%} \mathbf{C l}$ \\
\hline $\begin{array}{l}\text { Surgery type } \\
\text { RYGB }\end{array}$ & Ref & \\
SG & 1.89 & $0.91-3.91$ \\
Gender & & \\
$\quad$ Female & Ref & \\
$\quad$ Male & 2.28 & $1.14-4.56$ \\
Age & 1.05 & $1.01-1.09$ \\
Preoperative BMI & 1.03 & $0.97-1.09$ \\
Preoperative DM & 3.33 & $1.71-6.50$ \\
Preoperative low HDL & 2.28 & $1.17-4.48$ \\
\hline
\end{tabular}

Abbreviations: BMI, body mass index; DM, diabetes mellitus; $\mathrm{HDL}$, high-density lipoprotein; MetS, metabolic syndrome; RYGB, Roux-en-Y gastric bypass; SG, sleeve gastrectomy.

significant differences persisted after propensity matching. No significant differences occurred in rates of vitamin $\mathrm{D}$ or iron deficiency, chronic nausea, vomiting, or abdominal pain in the matched cohort.

\section{Discussion}

This study presents 4-year outcome data on metabolic syndrome, weight loss, and complications after SG and RYGB
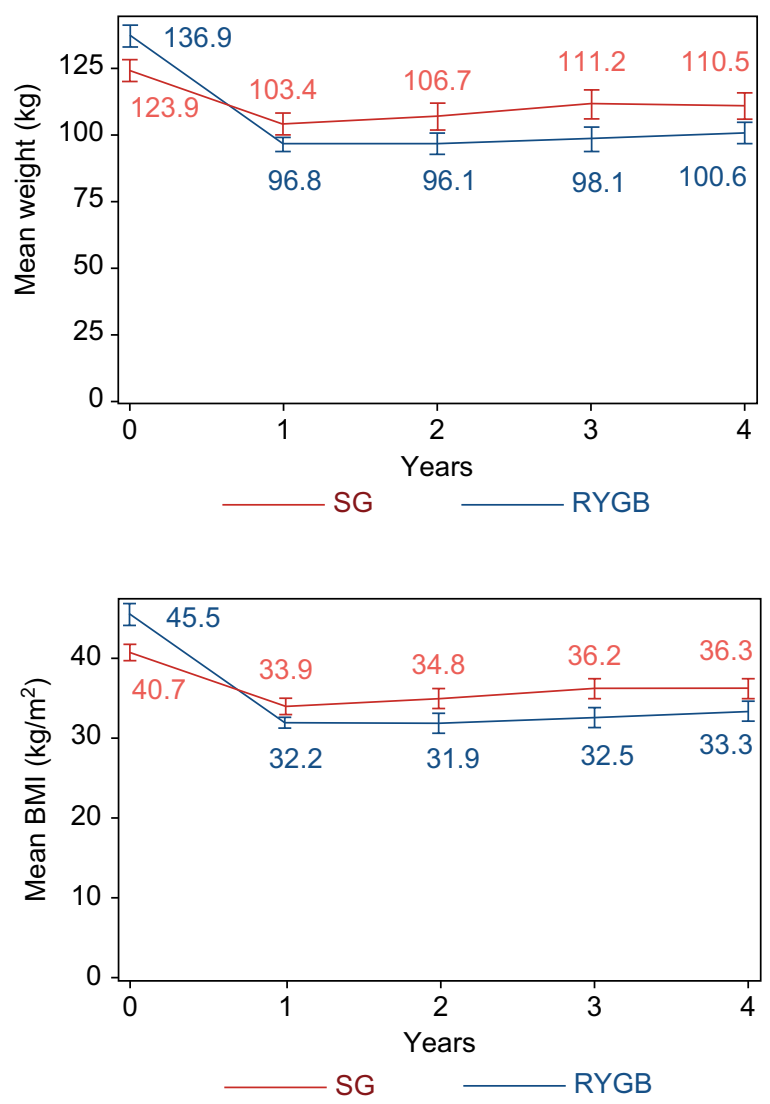

in a near-complete cohort of US veterans. In spite of significantly more weight loss in the RYGB cohort, the difference in metabolic syndrome remission was not significantly greater than for SG, but the rate of postoperative complications was higher in the RYGB group.

At 4 years of follow-up, both RYGB and SG reduced the prevalence of metabolic syndrome by $37.6 \%$ and $26.8 \%$, respectively. Weight loss was greatest in both the groups after the first year (RYGB $28.7 \%$ vs SG $16.8 \% ; P<0.01$ ), with weight regain occurring after the first year in the $\mathrm{SG}$ group and after the second year in the RYGB group.

Few studies report the effect of bariatric surgery on metabolic syndrome but instead focus on individual components such as hypertension, hypertriglyceridemia, hyperglycemia, or T2DM..$^{20}$ Reporting the effect of bariatric surgery on metabolic syndrome as an aggregate of cardiovascular risk factors, instead of its individual components, is helpful in quantifying the magnitude of metabolic improvement and projected decrease in cardiovascular morbidity and mortality between these two procedures. ${ }^{21-23}$ The majority of bariatric studies reporting the effect of surgery on metabolic syndrome involve subjects who have undergone RYGB and not SG.
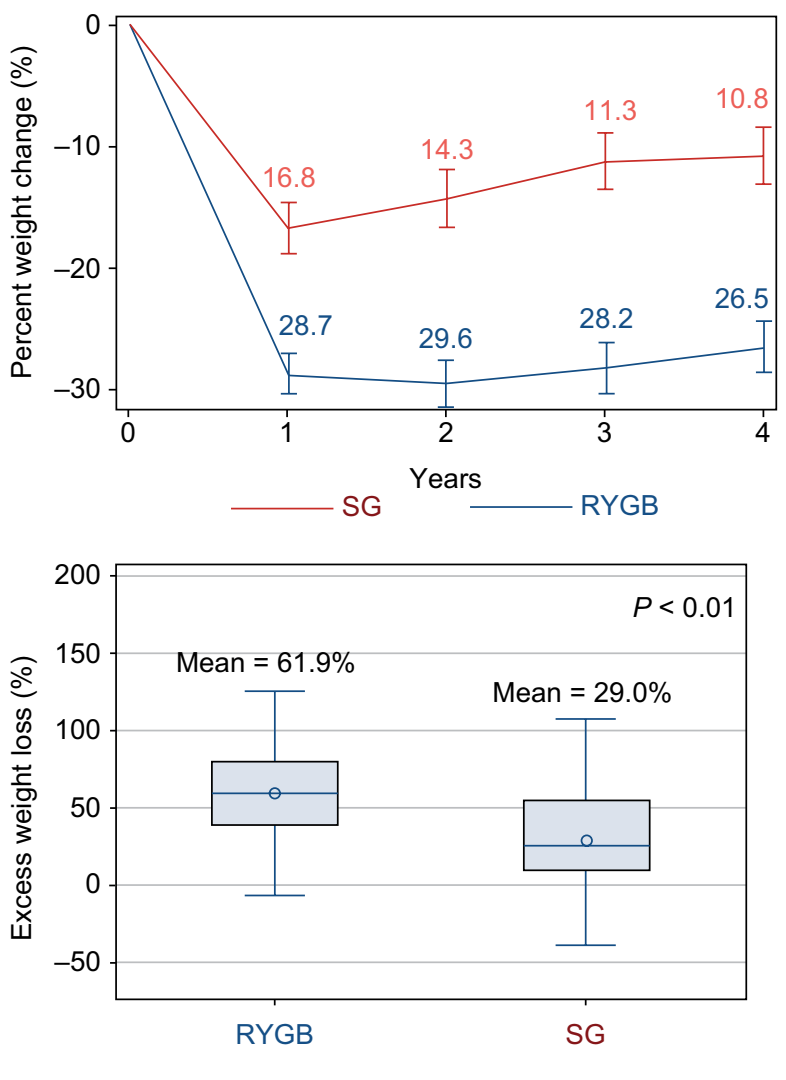

Figure I Weight $(\mathrm{kg})$, body mass index $\left(\mathrm{kg} / \mathrm{m}^{2}\right)$, percent weight change $(\%)$, and excess weight loss (\%) per procedure type for the entire cohort. Abbreviations: BMI, body mass index; RYGB, Roux-en-Y gastric bypass; SG, sleeve gastrectomy. 

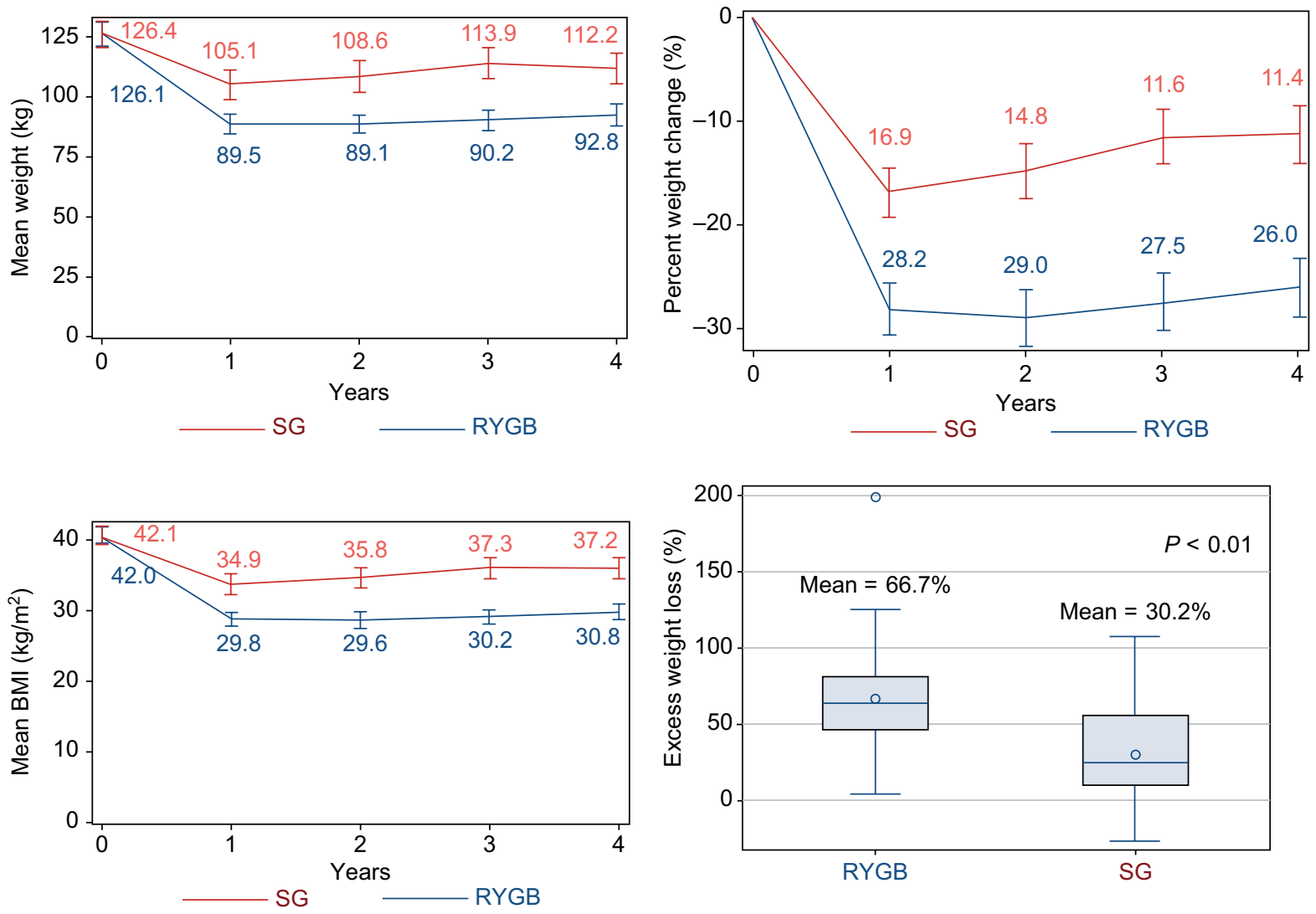

Figure 2 Weight $(\mathrm{kg})$, body mass index $\left(\mathrm{kg} / \mathrm{m}^{2}\right)$, percent weight change (\%), and excess weight loss (\%) per procedure type for the matched cohort. Abbreviations: BMI, body mass index; RYGB, Roux-en-Y gastric bypass; SG, sleeve gastrectomy.

Table 4 >30 day-morbidity and mortality following RYGB and SG

\begin{tabular}{|c|c|c|c|c|c|c|}
\hline & \multicolumn{3}{|l|}{ Entire cohort } & \multicolumn{3}{|c|}{ Matched cohort } \\
\hline & $\begin{array}{l}\text { RYGB } \\
\text { (total = I 59), } \\
\text { n (\%) }\end{array}$ & $\begin{array}{l}\text { SG } \\
(\text { total = I07), } \\
\text { n (\%) }\end{array}$ & $P$-value & $\begin{array}{l}\text { RYGB } \\
(\text { total = 65), } \\
n(\%)\end{array}$ & $\begin{array}{l}\text { SG } \\
(\text { total = 65), } \\
\text { n (\%) }\end{array}$ & $P$-value \\
\hline Mortality $>30$ days & $7(4.4)$ & $3(2.8)$ & 0.74 & & & \\
\hline Reoperations & $31(19.5)$ & $3(2.8)$ & $<0.01$ & 14 (21.9) & $3(4.8)$ & $<0.01$ \\
\hline Cholecystectomy & II (6.9) & $0(0)$ & $<0.01$ & $7(10.9)$ & $0(0)$ & 0.01 \\
\hline GI bleed & $2(1.3)$ & $0(0)$ & 0.52 & $2(3.1)$ & $0(0)$ & 0.50 \\
\hline Ulcer & $15(9.4)$ & $\mathrm{I}(0.9)$ & $<0.01$ & $7(10.9)$ & $0(0)$ & 0.01 \\
\hline Vitamin $B_{12}$ deficiency & $47(29.6)$ & $8(7.5)$ & $<0.01$ & $24(37.5)$ & $8(12.9)$ & $<0.01$ \\
\hline Vitamin D deficiency & $6(3.8)$ & II (I0.3) & 0.04 & $2(3.1)$ & $7(11.3)$ & 0.09 \\
\hline Iron deficiency & $30(18.9)$ & $10(9.4)$ & 0.04 & $16(25.0)$ & $8(12.9)$ & 0.11 \\
\hline Other nutritional deficiencies & $7(4.4)$ & $\mathrm{I}(0.9)$ & 0.15 & $3(4.7)$ & $\mathrm{I}(1.6)$ & 0.62 \\
\hline Chronic nausea/vomiting & II (6.9) & $3(2.8)$ & 0.17 & $7(10.9)$ & $3(4.8)$ & 0.32 \\
\hline Chronic pain & $6(3.8)$ & I (0.9) & 0.25 & $4(6.3)$ & I (I.6) & 0.37 \\
\hline
\end{tabular}

Abbreviations: RYGB, Roux-en-Y gastric bypass; SG, sleeve gastrectomy.

To our knowledge, this is the first 4-year study reporting the effect of both RYGB and SG on metabolic syndrome.

The remission rates of metabolic syndrome in our cohort at 4-year follow-up were lower than those reported from other groups. Studies following patients from 6 to 36 months after surgery yielded remission rates of 58\%-96\%. ${ }^{24-27}$ Shah et al, at a minimum of 5 years after RYGB, reported a metabolic syndrome remission rate of $86 \%{ }^{28}$ In general, these studies followed younger and predominantly female cohorts with a lower baseline prevalence of metabolic syndrome, assessed outcomes after RYGB, used different definitions of metabolic syndrome, ${ }^{29,30}$ and had greater cohort attrition. Batsis et al reporting on metabolic syndrome for both RYGB and SG at $\sim 3$ years after surgery, with similar baseline prevalence to 
our study, also reported higher metabolic syndrome remission rates of $58 \%$ and $59 \%$ (RYGB and SG, respectively). ${ }^{31}$ Similar to our findings, Batsis et al found no significant difference in metabolic syndrome remission between operations. It is challenging to compare the results across studies because of differences in the study populations, baseline prevalence of metabolic syndrome, definition criteria for metabolic syndrome, and follow-up intervals. Overall, bariatric surgery is effective at reducing the prevalence of metabolic syndrome and the risk of cardiovascular events.

In this study, RYGB was similar to SG with respect to the remission of hyperglycemia and hypertension. However, the decrease in the prevalence of hyperglycemia in the SG group did not reach statistical significance in spite of similarities in baseline fasting glucose, $\mathrm{HbAlc}$, the prevalence of diabetes, and insulin use between the surgical groups. This difference may be explained by the greater magnitude of weight loss in the RYGB group. The RYGB group experienced a greater reduction in the prevalence of hypertriglyceridemia than the SG group. Malabsorption resulting from decreased exposure of digested food to intestinal villi after RYGB may explain the greater improvement in TG level versus SG. Also, the magnitude of the reduction of TGs has been shown to be directly related to the amount of weight lost. ${ }^{32,33}$ The greater degree of weight loss alone, in the RYGB group, may explain the greater reducing of hypertriglyceridemia versus SG.

Randomized controlled trials have demonstrated similar efficacy of SG and RYGB for weight loss ${ }^{13,34,35}$ or diabetes. ${ }^{5}$ These studies had relatively small sample sizes and varying follow-up times and are not always powered to detect the differences between the operations. Large retrospective studies have shown, similar to our results, that RYGB seems to be more effective than SG for weight reduction. ${ }^{36,37}$ The Michigan Bariatric Surgery Collaborative found that RYGB patients had more weight loss than SG $(67 \%$ vs $56 \%$, respectively; $P=0.0004$ ) at a 3 -year follow-up. However, weight loss data were available for $<4 \%$ of subjects at the 3 -year time point. ${ }^{36}$ RYGB may lead to greater weight loss in men than in women when compared with SG. It is proposed that the combination of gastric restriction and malabsorption from the intestinal bypass in RYGB makes it a more effective weight loss operation than SG's gastric restriction alone. There is also evidence for significantly greater levels of glucagon-like peptide-1, a hormone conferring satiety, ${ }^{34}$ postoperatively and up to 1 year after RYGB versus SG, perhaps contributing to greater weight loss within the first year of surgery or beyond.

A recent study in veterans compared 1785 patients who underwent RYGB with 379 who underwent SG. ${ }^{37}$ Those in the RYGB group lost significantly more total weight than those in the SG group $(27.5 \%, 95 \% \mathrm{CI}, 23.8 \%-31.2 \%$ vs $17.8 \%, 95 \%$ CI, 9.7\%-25.9\%, respectively). This study had a follow-up rate of $47.7 \%$ for the SG group, which may have led to an overestimation of treatment results. Despite the potential overestimation of weight loss, our study, with a follow-up rate of $96 \%$, supports weight loss consistent with the confidence limits reported by Maciejewski et $\mathrm{al}^{37}$ and the finding of greater weight loss after RYGB than SG at 4 years.

The favorable complication rate of SG relative to RYGB is consistent with the short-term postoperation literature. ${ }^{35,38}$ Limited data is available on the long-term complications, particularly after SG. ${ }^{14}$ The greater reoperation rate over 4 years after RYGB was attributable to incisional hernia repairs, perforated gastric ulcers, bowel obstructions from adhesions, and gastrojejunal strictures after failed endoscopic dilation. The majority of RYGB were performed using an open approach; fewer reoperations for incisional hernia would be expected had the approach been laparoscopic. ${ }^{39}$ The higher rate of ulcers after RYGB is due to the presence of a gastrojejunal anastomosis leading to marginal ulceration from acid-mediated erosions of the jejunal mucosa and/or from ischemia. ${ }^{40}$ This does not occur with SG as normal continuity of the upper gastrointestinal system is not interrupted, nor is there an anastomosis. Vitamin $\mathrm{B}_{12}$ deficiency is more common following RYGB because the gastric pouch of the RYGB is composed mostly of gastric cardia and is smaller than the residual stomach in SG, leading to a near-exclusion of intrinsic factor-producing parietal cells. Intrinsic factor, required for vitamin $\mathrm{B}_{12}$ absorption, is either absent or produced at very low levels, resulting in $\mathrm{B}_{12}$ deficiency if not supplemented. Also, intestinal bypass malabsorption and/ or dumping syndrome after RYGB may contribute to the deficiency in vitamin $B_{12}$ and other nutrients.

Limitations of this study include its retrospective design, which can introduce selection bias and incomplete data collection. While we attempted to reduce bias with a secondary propensity-matched analysis, factors not captured or unknown may affect the outcomes. BMI was used as a surrogate for waist circumference in keeping with the International Diabetes Federation definition of metabolic syndrome, as waist circumferences were not routinely collected. This substitution could affect the baseline prevalence of metabolic syndrome but should not affect the pre- and postoperative comparisons. In addition, this study evaluated a predominantly male and lower socioeconomic level population, which may limit its generalizability. Most bariatric populations are predominantly female and, aside from Medicare patients, 
represent a higher socioeconomic class of privately insured or self-pay patients. Finally, we did not have information on changes in other weight-dependent comorbidities such as obstructive sleep apnea, mechanical joint disease, and urinary incontinence. Despite these limitations, the duration of follow-up, the high degree of cohort retention, and the reporting of complications provided a unique opportunity for evaluating the relative treatment benefits in this population.

\section{Conclusion}

This study shows that in a US veteran population, RYGB and SG procedures were associated with similar rates of remission of metabolic syndrome at 4 years in spite of greater weight loss and complications in the RYGB group. Though a long-term randomized trial comparing the effects of both the operations on metabolic syndrome remission as well as the associated risks of surgery may clarify/validate our findings, the feasibility and cost of such a trial preclude the likelihood of it occurring.

\section{Acknowledgments}

We appreciate the editorial support of Dave Primm, MA (Dallas, TX). We also appreciate the support of Kim Hopson, PA-C; Grayce Mitchell, PA-C; and Julie Santarosa, MD (Dallas, TX, for all), who together ensured complete patient follow-up.

The study was supported by the National Center for Advancing Translational Sciences of the National Institutes of Health under award number UL1TR001105. The content is solely the responsibility of the authors and does not necessarily represent the official views of the NIH.

\section{Disclosure}

The authors report no conflicts of interest in this work.

\section{References}

1. Sundström J, Risérus U, Byberg L, Zethelius B, Lithell H, Lind L. Clinical value of the metabolic syndrome for long term prediction of total and cardiovascular mortality: prospective, population based cohort study. BMJ. 2006;332(7546):878-882.

2. Alberti KG, Eckel RH, Grundy SM, et al. Harmonizing the metabolic syndrome: a joint interim statement of the International Diabetes Federation Task Force on Epidemiology and Prevention; National Heart, Lung, and Blood Institute; American Heart Association; World Heart Federation; International Atherosclerosis Society; and International Association for the Study of Obesity. Circulation. 2009;120(16):1640-1645.

3. National Institutes of Health. Gastrointestinal surgery for severe obesity: National Institutes of Health Concensus Development Conference statement. Am J Clin Nutr. 1992;55(Suppl 2):615s-619s.

4. Colquitt JL, Pickett K, Loveman E, Frampton GK. Surgery for weight loss in adults. Cochrane Database Syst Rev. 2014;8:CD003641.

5. Schauer PR, Bhatt DL, Kirwan JP, et al.; STAMPEDE investigators. Bariatric surgery versus intensive medical therapy for diabetes -5 -year outcomes. N Engl J Med. 2017;376(7):641-651.
6. Guo X, Liu X, Wang M, Wei F, Zhang Y, Zhang Y. The effects of bariatric procedures versus medical therapy for obese patients with type 2 diabetes: meta-analysis of randomized controlled trials. Biomed Res Int. 2013;2013:410609.

7. Arterburn DE, Olsen MK, Smith VA, et al. Association between bariatric surgery and long-term survival. JAMA. 2015;313(1):62-70.

8. Adams TD, Gress RE, Smith SC. Long-term mortality after gastric bypass surgery. N Engl J Med. 2007;357(8):753-761.

9. Sjöström L, Peltonen M, Jacobson P. Bariatric surgery and long-term cardiovascular events. JAMA. 2012;307(1):56-65.

10. Christou NV, Sampalis JS, Liberman M, et al. Surgery decreases longterm mortality, morbidity, and health care use in morbidly obese patients. Ann Surg. 2004;240(3):416-423; discussion 423-424.

11. Ponce J, Nguyen NT, Hutter M, Sudan R, Morton JM. American Society for Metabolic and Bariatric Surgery estimation of bariatric surgery procedures in the United States, 2011-2014. Surg Obes Relat Dis. 2015;11(6): 1199-1200.

12. Boza C, Gamboa C, Salinas J, Achurra P, Vega A, Pérez G. Laparoscopic Roux-en-Y gastric bypass versus laparoscopic sleeve gastrectomy: a casecontrol study and 3 years of follow-up. Surg Obes Relat Dis. 2012;8(3): 243-249.

13. Kehagias I, Karamanakos SN, Argentou M, Kalfarentzos F. Randomized clinical trial of laparoscopic Roux-en-Y gastric bypass versus laparoscopic sleeve gastrectomy for the management of patients with BMI $<50$ kg/m². Obes Surg. 2011;21(11):1650-1656.

14. Puzziferri N, Roshek TB 3rd, Mayo HG, Gallagher R, Belle SH, Livingston EH. Long-term follow-up after bariatric surgery: a systematic review. JAMA. 2014;312(9):934-942.

15. Peterli R, Wölnerhanssen BK, Vetter D, et al. Laparoscopic sleeve gastrectomy versus Roux-Y-gastric bypass for morbid obesity - 3-year outcomes of the Prospective Randomized Swiss Multicenter Bypass or Sleeve Study (SM-BOSS). Ann Surg. 2017;265(3):466-473.

16. Rutledge T, Braden AL, Woods G, Herbst KL, Groesz LM, Savu M. Five-year changes in psychiatric treatment status and weight-related comorbidities following bariatric surgery in a veteran population. Obes Surg. 2012;22(11):1734-1741.

17. Saul D, Stephens D, de Cassia Hofstätter R, Ahmed L, Langhoff E, Heimann TM. Preliminary outcomes of laparoscopic sleeve gastrectomy in a Veterans Affairs medical center. Am J Surg. 2012;204(5):e1-e6.

18. Huang PL. A comprehensive definition for metabolic syndrome. Dis Model Mech. 2009;2(5-6):231-237.

19. Ong KL, Tso AW, Lam KS, Cherny SS, Sham PC, Cheung BM. Using glycosylated hemoglobin to define the metabolic syndrome in United States adults. Diabetes Care. 2010;33(8):1856-1858.

20. Ricci C, Gaeta M, Rausa E, Asti E, Bandera F, Bonavina L. Longterm effects of bariatric surgery on type II diabetes, hypertension and hyperlipidemia: a meta-analysis and meta-regression study with 5-year follow-up. Obes Surg. 2015;25(3):397-405.

21. Kannel WB, McGeeDL. Diabetes and cardiovascular disease. The Framingham study. JAMA. 1979;241(19):2035-2038.

22. Rosengren A, Welin L, Tsipogianni A, Wilhelmsen L. Impact of cardiovascular risk factors on coronary heart disease and mortality among middle aged diabetic men: a general population study. BMJ. 1989;299(6708): $1127-1131$.

23. Stamler J, Vaccaro O, Neaton JD, Wentworth D. Diabetes, other risk factors, and 12-yr cardiovascular mortality for men screened in the Multiple Risk Factor Intervention Trial. Diabetes Care. 1993;16(2):434-444.

24. Rodríguez-Ortiz D, Reyes-Pérez A, León P. Assessment of two different diagnostic guidelines criteria (National Cholesterol Education Adult Treatment Panel III [ATP III] and International Diabetes Federation [IDF]) for the evaluation of metabolic syndrome remission in a longitudinal cohort of patients undergoing Roux-en-Y gastric bypass. Surgery. 2016;159(4):1121-1128.

25. Rossi M, Barretto Fereira da Silva R, Chaves Alcântara G Jr. Remission of metabolic syndrome: a study of 140 patients six months after Roux-en-Y gastric bypass. Obes Surg. 2008;18(5):601-606. 
26. Péquignot A, Dhahri A, Verhaeghe P, Desailloud R, Lalau JD, Regimbeau JM. Efficiency of laparoscopic sleeve gastrectomy on metabolic syndrome disorders: two years results. JVisc Surg. 2012;149(5):e350-e355.

27. Vidal J, Ibarzabal A, Romero F. Type 2 diabetes mellitus and the metabolic syndrome following sleeve gastrectomy in severely obese subjects. Obes Surg. 2008;18(9):1077-1082.

28. Shah K, Nergard BJ, Stray Frazier K, Geir Leifsson B, Aghajani E, Gislason H. Long-term effects of laparoscopic Roux-en-Y gastric bypass on metabolic syndrome in patients with morbid obesity. Surg Obes Relat Dis. 2016;12(8):1449-1456.

29. Expert Panel on Detection, Evaluation, and Treatment of High Blood Cholesterol in Adults (Adult Treatment Panel III). Executive summary of the third report of the National Cholesterol Education Program (NCEP). JAMA. 2001;285(19):2486-2497.

30. Alberti KG, Zimmet P, Shaw J; IDF Epidemiology Task Force Consensus Group. The metabolic syndrome - a new worldwide definition. Lancet. 2005;366(9491):1059-1062.

31. Batsis JA, Romero-Corral A, Collazo-Clavell ML, Sarr MG, Somers VK, Lopez-Jimenez F. Effect of bariatric surgery on the metabolic syndrome: a population-based, long-term controlled study. Mayo Clin Proc. 2008;83(8):897-907.

32. Anderson JW, Conley SB, Nicholas AS. One hundred pound weight losses with an intensive behavioral program: changes in risk factors in 118 patients with long-term follow-up. Am J Clin Nutr. 2007;86(2):301-307.

33. Wing RR, Lang W, Wadden TA, et al.; Look AHEAD Research Group Benefits of modest weight loss in improving cardiovascular risk factors in overweight and obese individuals with type 2 diabetes. Diabetes Care. 2011;34(7):1481-1486.
34. Peterli R, Steinert RE, Woelnerhanssen B. Metabolic and hormonal changes after laparoscopic Roux-en-Y gastric bypass and sleeve gastrectomy: a randomized, prospective trial. Obes Surg. 2012;22(5): 740-748.

35. Trastulli S, Desiderio J, Guarino S. Laparoscopic sleeve gastrectomy compared with other bariatric surgical procedures: a systematic review of randomized trials. Surg Obes Relat Dis. 2013;9(5):816-829.

36. Carlin AM, Zeni TM, English WJ, et al.; Michigan Bariatric Surgery Collaborative. The comparative effectiveness of sleeve gastrectomy, gastric bypass, and adjustable gastric banding procedures for the treatment of morbid obesity. Ann Surg. 2013;257(5):791-797.

37. Maciejewski ML, Arterburn DE, Van Scoyoc L, et al. Bariatric surgery and long-term durability of weight loss. JAMA Surg. 2016;151(11) 1046-1055.

38. Hutter MM, Schirmer BD, Jones DB, et al. First report from the American College of Surgeons Bariatric Surgery Center Network: laparoscopic sleeve gastrectomy has morbidity and effectiveness positioned between the band and the bypass. Ann Surg. 2011;254(3):410-420; discussion $420-422$.

39. Puzziferri N, Austrheim-Smith IT, Wolfe BM, Wilson SE, Nguyen NT. Three-year follow-up of a prospective randomized trial comparing laparoscopic versus open gastric bypass. Ann Surg. 2006;243(2):181-188.

40. Azagury DE, Abu Dayyeh BK, Greenwalt IT, Thompson CC. Marginal ulceration after Roux-en-Y gastric bypass surgery: characteristics, risk factors, treatment, and outcomes. Endoscopy. 2011;43(11): 950-954. 


\section{Supplementary materials}

Table SI Prevalence of metabolic syndrome and its components before ("Pre") and 4 years following ("Post") RYGB and SG for the matched cohort

\begin{tabular}{|c|c|c|c|c|c|c|c|}
\hline & \multicolumn{2}{|c|}{ RYGB $(n=65)$} & \multirow{2}{*}{$\begin{array}{l}\text { Paired test } \\
\text { P-value } \\
\text { (McNemar) }\end{array}$} & \multicolumn{2}{|c|}{ SG $(n=65)$} & \multirow{2}{*}{$\begin{array}{l}\text { Paired test } \\
\text { P-value } \\
\text { (McNemar) }\end{array}$} & \multirow{2}{*}{$\begin{array}{l}\text { Interaction } \\
P \text {-value }\end{array}$} \\
\hline & Pre n (\%) & Post n (\%) & & Pre n (\%) & Post n (\%) & & \\
\hline Obesity & $65(100)$ & $39(60.0)$ & $<0.01$ & $65(100)$ & $57(87.7)$ & $<0.01$ & $<0.01$ \\
\hline Hyperglycemia & $51(78.5)$ & $40(6 I .5)$ & 0.01 & $49(75.4)$ & $45(75.0)$ & 0.74 & 0.06 \\
\hline Hypertriglyceridemia & $32(50)$ & $8(12.5)$ & $<0.01$ & $31(49.2)$ & $22(34.4)$ & 0.039 & $<0.01$ \\
\hline Low HDL-C & $33(51.6)$ & $10(15.6)$ & $<0.01$ & $31(49.2)$ & II (I7.5) & $<0.01$ & 0.68 \\
\hline Hypertension & 61 (93.9) & $55(84.6)$ & 0.03 & $62(95.4)$ & $43(66.2)$ & $<0.01$ & 0.09 \\
\hline Metabolic syndrome & 57 (87.7) & $31(47.7)$ & $<0.01$ & 57 (87.7) & $39(60.0)$ & $<0.01$ & 0.34 \\
\hline
\end{tabular}

Abbreviations: HDL-C, high-density lipoprotein cholesterol; RYGB, Roux-en-Y gastric bypass; SG, sleeve gastrectomy

VA patients who underwent RYGB or SG from 2003 to $2012(n=266)$

RYGB ( $n=159)$, SG ( $n=107)$

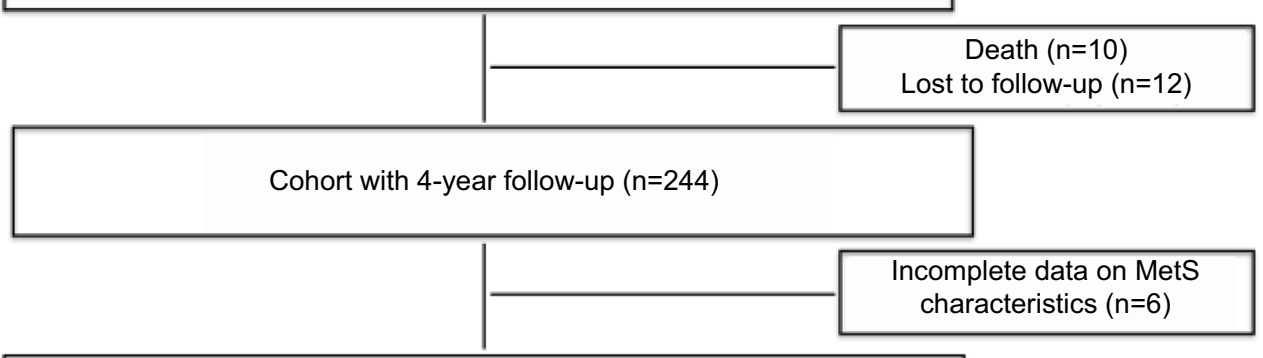

Cohort with complete 4-year follow-up and used for 1:1 propensity matching RYGB ( $n=141)$, SG ( $n=97)$

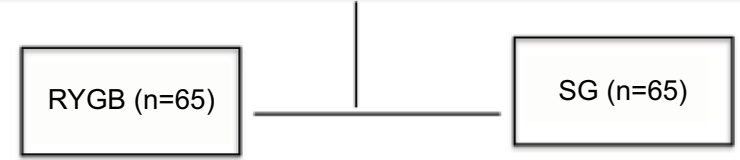

Figure SI Flowchart of cohort sample size for analyses.

Abbreviations: MetS, metabolic syndrome; RYGB, Roux-en-Y gastric bypass; SG, sleeve gastrectomy; VA, Veterans Affairs.

Diabetes, Metabolic Syndrome and Obesity: Targets and Therapy is an international, peer-reviewed open-access journal committed to the rapid publication of the latest laboratory and clinical findings in the fields of diabetes, metabolic syndrome and obesity research. Original research, review, case reports, hypothesis formation, expert opinion and commentaries are all considered for publication. The manuscript management system is completely online and includes a very quick and fair peer-review system, which is all easy to use. Visit http://www.dovepress.com/testimonials.php to read real quotes from published authors. 